\title{
Lactobacillus arizonensis is a later heterotypic synonym of Lactobacillus plantarum
}

\author{
Correspondence \\ Charles M. A. P. Franz \\ Charles.Franz@bfe. \\ uni-karlsruhe.de
}

\author{
Melanie Kostinek, ${ }^{1}$ Rüdiger Pukall, ${ }^{2}$ Alejandro P. Rooney, ${ }^{3}$ \\ Ulrich Schillinger, ${ }^{1}$ Christian Hertel, ${ }^{4}$ Wilhelm H. Holzapfel ${ }^{1}$ \\ and Charles M. A. P. Franz ${ }^{1}$
}

\begin{abstract}
${ }^{1}$ Federal Research Centre for Nutrition and Food, Institute for Hygiene and Toxicology, Haidund-Neu-Strasse 9, D-76131 Karlsruhe, Germany

${ }^{2} \mathrm{DSMZ}$ - Deutsche Sammlung von Mikroorganismen und Zellkulturen GmbH, Mascheroder Weg 1b, D-38124 Braunschweig, Germany

${ }^{3}$ US Department of Agriculture, Agricultural Research Service, National Center for Agricultural Utilization Research, ARS Culture Collection, Peoria, IL 61604, USA

${ }^{4}$ Institute of Food Technology, University of Hohenheim, Garbenstrasse 28, D-70599 Stuttgart, Germany
\end{abstract}

The 'Lactobacillus plantarum group' encompasses the taxa Lactobacillus plantarum subsp. plantarum, Lactobacillus plantarum subsp. argentoratensis, Lactobacillus paraplantarum, Lactobacillus pentosus and Lactobacillus arizonensis. In this study, the phylogenetic position of $L$. arizonensis was examined using 16S rRNA gene-specific methodologies (16S rRNA sequencing and ribotyping) and genomic DNA-based investigations [repetitive extragenic palindromic DNA (rep)-PCR and DNA-DNA hybridization]. Our results show that the $L$. arizonensis type strain could not be distinguished from the type strain of $L$. plantarum or from various $L$. plantarum reference strains. Therefore, it is proposed that the species $L$. arizonensis should be reclassified as a heterotypic synonym of L. plantarum.
The Lactobacillus species L. plantarum (subsp. plantarum and subsp. argentoratensis), L. paraplantarum, L. pentosus and $L$. arizonensis form a closely related group known as the 'Lactobacillus plantarum group' (LPG). All of these species are facultatively heterofermentative, produce DL-lactate, contain meso-diaminopimelic acid in their cell wall (Curk et al., 1996; Hammes \& Hertel, 2003) and are difficult to distinguish from each other by phenotypic characteristics alone. Nevertheless, L. pentosus is generally positive for xylose fermentation, whereas $L$. arizonensis and L. paraplantarum are unable to ferment this carbohydrate (Kandler \& Weiss, 1986; Zanoni et al., 1987; Swezey et al., 2000). Unlike L. plantarum and L. paraplantarum, L. pentosus ferments glycerol but not melezitose (Zanoni et al., 1987; Bringel et al., 1996; Curk et al., 1996).

Published online ahead of print on 29 July 2005 as DOI 10.1099/ ijs.0.63880-0.

Abbreviation: rep-PCR, repetitive extragenic palindromic DNA-PCR.

The GenBank/EMBL/DDBJ accession numbers for the partial nucleotide sequences of the $16 \mathrm{~S}$ rRNA gene of $L$. arizonensis strains NRRL B-14768' ${ }^{\top}$, NRRL B-14769, NRRL B-14770, NRRL B-14771, NRRL B-14772 and DSM 13273' are AJ965482, AJ965483, AJ965484, AJ965485, AJ965486 and AJ965487, respectively.
The 16S rRNA gene sequences of the species of the LPG are highly similar (99.7-99.9\%) and, therefore, are also of limited utility in differentiating species (Bringel et al., 1996; Hammes \& Hertel, 2003). On the other hand, L. plantarum, L. plantarum subsp. argentoratensis, L. pentosus and $L$. paraplantarum can be reliably differentiated from one another by using other molecular techniques. For example, probes targeted against specific genes ( $p y r D E F)$, were successfully used to differentiate between the closely related species L. plantarum, L. pentosus and L. paraplantarum (Bringel et al., 1996; Quere et al., 1997). DNA-DNA hybridization also clearly distinguishes between L. plantarum, L. pentosus and L. paraplantarum (Dellaglio et al., 1975; Zanoni et al., 1987; Curk et al., 1996).

L. arizonensis is the most recently described member of the LPG (Swezey et al., 2000). It was originally described as a unique LPG species capable of degrading simmondsin at $45^{\circ} \mathrm{C}$ and was elevated to species-level status on the basis of this characteristic, as well as 16S rRNA gene sequence divergence and DNA-DNA hybridization data (Swezey et al., 2000). In this study, we show that the type strain of $L$. arizonensis (NRRL B-14768 ${ }^{\mathrm{T}}=\mathrm{DSM} 13273^{\mathrm{T}}$ ) is not distinguishable from the L. plantarum type strain (DSM 20174 ${ }^{\mathrm{T}}$ ) on the basis of ribotyping patterns, repetitive extragenic palindromic DNA (rep)-PCR fingerprinting patterns, 16S 
Table 1. LPG strains used in this study

\begin{tabular}{|lc|}
\hline Strain & \multicolumn{1}{c|}{ Source } \\
\hline L. plantarum DSM $20174^{\mathrm{T}}$ & DSMZ \\
L. pentosus DSM 20314 & DSMZ \\
L. paraplantarum DSM $10667^{\mathrm{T}}$ & DSMZ \\
L. arizonensis & \\
NRRL B-14768 & \\
$\left(=\right.$ DSM $\left.13273^{\mathrm{T}}\right)$ & ARS Culture Collection, \\
NRRL B-14769 & (DSMZ) \\
NRRL B-14770 & ARS Culture Collection \\
NRRL B-14771 & ARS Culture Collection \\
NRRL B-14772 & ARS Culture Collection \\
& ARS Culture Collection \\
\hline
\end{tabular}

rRNA gene sequences and DNA-DNA hybridization data, indicating that the previously described taxon $L$. arizonensis is a later heterotypic synonym of $L$. plantarum.

The bacterial strains used in this study are listed in Table 1. Type strains for L. plantarum, L. pentosus and L. paraplantarum were obtained from the Deutsche Sammlung von Mikroorganismen und Zellkulturen (DSMZ) and several $L$. arizonensis reference strains were obtained from the US Department of Agriculture, Agricultural Research Service (ARS) Culture Collection (formerly known as NRRL). Two preparations of the $L$. arizonensis type strain were also used; these came from the DSMZ and the ARS Culture Collection.

Automated ribotyping was performed using the DuPont Qualicon RiboPrinter system (Bruce, 1996) and with EcoRI as the standard restriction enzyme. The band patterns were compared using Bionumerics software (Applied Maths). Clustering was performed by the unweighted pair group method with arithmetic means (UPGMA) (Sneath \& Sokal, 1973) based on the Pearson product-moment correlation coefficient, using an optimization coefficient of $1 \cdot 2 \%$. The riboprinting patterns obtained from the LPG strains are shown in Fig. 1. In addition to the type strains, additional LPG reference strains were included in order to obtain a broader representation of the LPG species. Strains belonging to $L$. pentosus, $L$. paraplantarum and L. plantarum subsp. argentoratensis each formed a separate cluster, whereas both of the L. paraplantarum strains could be assigned to the same group. Comparison of the latter two fingerprint patterns showed a similarity value of $88.8 \%$. In contrast, the riboprints of $L$. plantarum and L. arizonensis strains could be allocated to three different groups. The first group (1) clustered closely at $r=89 \%$ and included the type strain of L. plantarum DSM $20174^{\mathrm{T}}$, the L. plantarum strains DSM 2601, DSM 2648 and DSM 20246, as well as the type strains $\left(\right.$ NRRL B-14768 $\left.{ }^{\mathrm{T}}=\mathrm{DSM} 13273^{\mathrm{T}}\right)$ and strain NRRL B14769 , recently described as L. arizonensis. L. plantarum strain DSM 20205 formed a separate group (group 2). The remaining strains of L. arizonensis (NRRL B-14770, NRRL B-14771, NRRL B-14772), which also clustered closely ( $r=$ $90 \%$ ), formed the third group which also included the strain L. plantarum DSM 12028 (group 3; Fig. 1).

Total genomic DNA was isolated from the LPG bacteria listed in Table 1 according to the method of Pitcher et al. (1989), as modified by Björkroth \& Korkeala (1996), which relies on using a combined lysozyme and mutanolysin treatment. The genomic DNA was used for amplification of the 16S rRNA gene and for rep-PCR fingerprinting. Rep-PCR fingerprinting was conducted using the primer (GTG)5 (5'-GTGGTGGTGGTGGTG-3') and the methods described by Gevers et al. (2001), with slight modifications as described by Kostinek et al. (2005). Rep-PCR fingerprints were analysed using the BioNumerics (version 2.5) software package (Applied Maths). Groupings of the repPCR fingerprints were performed by using the Pearson product-moment correlation coefficient $(r)$ and the UPGMA clustering algorithm (Sneath \& Sokal, 1973).
Fig. 1. Cluster analysis of riboprint patterns obtained from strains closely related to $L$. plantarum. 

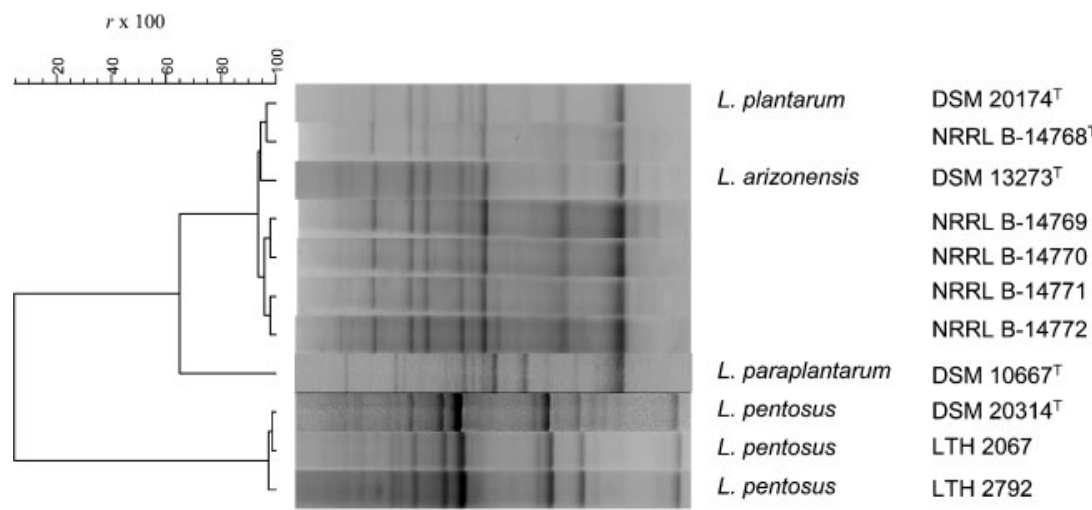

Fig. 2. UPGMA tree obtained from correlation values of rep-PCR fingerprint patterns of $L$. arizonensis, L. plantarum, L. paraplantarum and $L$. pentosus type and reference strains.

Using rep-PCR, the L. plantarum type strain (DSM 20174 ${ }^{\mathrm{T}}$ ) and $L$. arizonensis type strain (NRRL B-14768 ${ }^{\mathrm{T}}=\mathrm{DSM}$ $13273^{\mathrm{T}}$ ) grouped closely at $r=94 \cdot 3 \%$ (Fig. 2). Furthermore, these grouped closely together with the other $L$. arizonensis strains NRRL B-14769, NRRL B-14770, NRRL B-14771 and NRRL B-14772 at $r=93 \cdot 6 \%$. Using rep-PCR, these strains (including the $L$. arizonensis and L. plantarum type strains) could be well distinguished from L. paraplantarum DSM $10667^{\mathrm{T}}$ and L. pentosus DSM $20314^{\mathrm{T}}$, which grouped together with the L. plantarum/L. arizonensis strains at $r=64.9 \%$ and $r=4.5 \%$, respectively (Fig. 2).

The almost-complete 16S rRNA genes of all the LPG strains were amplified and sequenced at GATC Biotech, following the methods of Yousif et al. (2005). The 16S rRNA of the $L$. arizonensis type and reference strains was amplified and sequenced independently at the ARS Culture Collection as described previously by Rooney et al. (2005). For phylogenetic analysis, the complete $16 \mathrm{~S}$ rRNA gene sequences were fitted into an alignment of at least $90 \%$ complete primary structure available in public databases using the respective tools of the ARB software package (Ludwig et al., 2004).

16S rRNA gene sequencing showed that the sequence of the L. arizonensis strains DSM $13273^{\mathrm{T}}$, NRRL B-14768 ${ }^{\mathrm{T}}$, NRRL B-14769, NRRL B-14770, NRRL B-14771 and NRRL B14772 exhibited high $(>99 \cdot 4 \%)$ similarity to the corresponding 16S rRNA nucleotide sequences of L. plantarum DSM $20174^{\mathrm{T}}$, L. pentosus DSM $20314^{\mathrm{T}}$ and L. paraplantarum DSM $10667^{\mathrm{T}}$. In contrast, the level of similarity of these sequences to the $16 \mathrm{~S}$ rRNA gene sequence deposited in the EMBL nucleotide database for L. arizonensis NRRL B- $14768^{\mathrm{T}}$ (GenBank accession number AF093757) was noticeably lower, at $97 \cdot 2 \%$. The phylogenetic tree showing the position of strains DSM $13273^{\mathrm{T}}$ and NRRL B-14768 compared with their nearest phylogenetic neighbours is shown in Fig. 3. The $16 \mathrm{~S}$ rRNA gene sequences obtained for strains DSM $13273^{\mathrm{T}}$, NRRL B-14768 ${ }^{\mathrm{T}}$, NRRL B-14769, NRRL B-14770, NRRL B-14771 and NRRL B-14772 in this study are almost identical, except for the NRRL B-14772 sequence, which is missing one base (adenine) in the 90110 region (Escherichia coli numbering system), and the sequence of strain NRRL B-14770, which differs in one base in the 180-220 region (E. coli numbering system). The phylogenetic analysis shows that the 16S rRNA gene sequence deposited for L. arizonensis (AF093757) by Swezey et al. (2000) resulted in a noticeably divergent positioning of this species relative to other LPG species (Fig. 3).

LPG taxa are difficult to separate on the basis of $16 \mathrm{~S}$ rRNA gene sequence similarity. Thus, it is somewhat surprising that the original $L$. arizonensis strain NRRL B-14768 ${ }^{\mathrm{T}}$ $16 \mathrm{~S}$ rRNA gene sequence (GenBank accession number AF093757) displays so many nucleotide differences from the L. plantarum and L. paraplantarum 16S rRNA gene sequences, as this stands in stark contrast to the otherwise close relatedness in phenotypic and genotypic properties, including 16S rRNA gene sequence relatedness, among other LPG strains and species. Moreover, many of the differences between the original $L$. arizonensis $16 \mathrm{~S}$ rRNA gene sequence and the other LPG 16S rRNA gene sequences are in conserved regions of the $16 \mathrm{~S}$ rRNA molecule. This observation suggests that the 16S rRNA gene sequence differences between L. arizonensis as originally described and the other LPG species were most likely based on errors. Thus, we believe that the $16 \mathrm{~S}$ rRNA gene sequence as deposited by Swezey et al. (2000) was possibly based on a contaminated culture or sequencing error. According to the results of this study, the $16 \mathrm{~S}$ rRNA gene sequences of the strains L. arizonensis DSM $13273^{\mathrm{T}}$ and NRRL B-14768 ${ }^{\mathrm{T}}$ deposited in both the DMSZ culture collection (GenBank accession number AJ965482) and the ARS Culture Collection clearly represent strains of L. plantarum.

For determination of the DNA base composition and DNADNA hybridization values, DNA was isolated and purified according to the method of Marmur (1961) as modified by Stackebrandt \& Kandler (1979). The DNA base composition $(\mathrm{G}+\mathrm{C}$ mol\%) was determined from the thermal melting temperature $\left(T_{\mathrm{m}}\right)$ of DNA using a spectrophotometer $(100$ Bio UV-Visible; Varian Cary). DNA-DNA relatedness was determined spectrophotometrically from renaturation rates according to De Ley et al. (1970). The DNA of representative strains belonging to ribotyping groups 1 and 3 showed DNA-DNA relatedness values with strain NRRL B-14768 ${ }^{\mathrm{T}}$ of greater than $70 \%$ (Table 2). Strains NRRL B-14768 ${ }^{\mathrm{T}}$, 


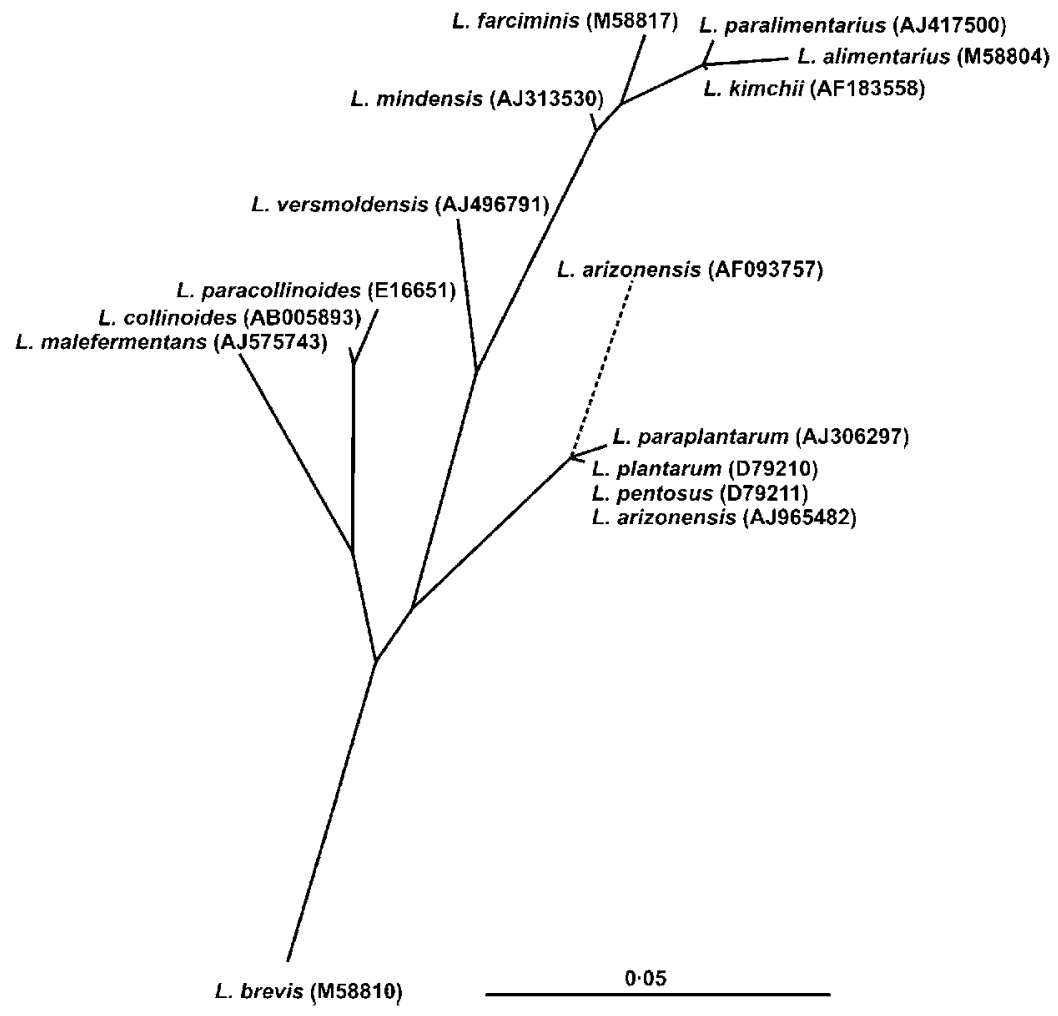

Fig. 3. Phylogenetic tree reflecting the relationship among members of the LPG. The tree is based on a maximum-parsimony analysis of all available at least $90 \%$ complete 16S rRNA gene sequences of the family Lactobacillaceae. Alignment positions that share identical residues in at least $50 \%$ of all sequences of the genera Lactobacillus and Pediococcus were considered. The tree topology was indicated by the positions of the type strain sequences. Bar, 5\% estimated sequence divergence.

NRRL B-14769, DSM 20246, DSM $20174^{\mathrm{T}}$ and DSM $13273^{\mathrm{T}}$ all belonged to group 1 in the ribotyping experiments (Fig. 1) and revealed a high DNA-DNA relatedness value of between 73 and $100 \%$ with strain NRRL B-14768 ${ }^{\mathrm{T}}$. Strain NRRL B-14768 ${ }^{\mathrm{T}}$ also showed very high DNA-DNA relatedness (96\%) to strain NRRL B-14771, which belonged to group 3 according to the ribotyping results (Fig. 1). DNA-DNA hybridization of strain DSM $13273^{\mathrm{T}}$ with $L$. plantarum DSM $20174^{\mathrm{T}}$ (both from ribotyping group 1) resulted in a $100 \%$ relatedness value, while DNA-DNA

Table 2. DNA relatedness values to $L$. arizonensis NRRL $\mathrm{B}-14768^{\top}$ derived from DNA-DNA hybridization experiments

\begin{tabular}{|lcc|}
\hline & $\begin{array}{c}\text { Ribotyping } \\
\text { group }\end{array}$ & $\begin{array}{c}\text { DNA relatedness } \\
\text { value to } \text { L. arizonensis } \\
\text { NRRL B-14768 }\end{array}$ \\
\hline L. plantarum & \\
DSM 20246 & 1 & 82 \\
DSM 20174 & 1 & 73 \\
L. arizonensis & & \\
NRRL B-14769 & 1 & 94 \\
DSM 13273 & 1 & 100 \\
NRRL B-14771 & 3 & 89 \\
L. pentosus DSM & - & 53 \\
20314 & & \\
\hline
\end{tabular}

${ }^{\star}$ L. arizonensis NRRL B- $14768^{\mathrm{T}}$ is a member of ribotyping group 1, data from this study. hybridization of strain NRRL B-14771 (ribotyping group 3) with L. plantarum DSM $20174^{\mathrm{T}}$ (ribotyping group 1) led to a somewhat lower relatedness value of $75 \%$ (result not shown). Furthermore, the DNA-DNA relatedness value detected for strain NRRL B-14771 (ribotyping group 3) and strain DSM 20246 (ribotyping group 1) was $90 \%$ (result not shown).

Therefore, strains from both within and between the different ribotyping groups showed DNA-DNA relatedness values of $>70 \%$. This indicated that they are all members of the same species, as a reassociation value of $70 \%$ is considered to be the cut-off value for a species in DNADNA hybridization experiments (Wayne et al., 1987). Our DNA-DNA hybridization analyses showed that the $L$. arizonensis and $L$. plantarum type strains, as well as other representative $L$. arizonensis and $L$. plantarum strains, are clearly related at the species level. Previous data by Swezey et al. (2000) reported DNA-DNA relatedness values for $L$. plantarum DSM $20174^{\mathrm{T}}$ and L. arizonensis NRRL B-14768 ${ }^{\mathrm{T}}$ of $42 \%$, which is much lower than the value determined in our study. Again, we presume that a mixed culture may possibly have been used in the DNA-DNA hybridization experiments of Swezey et al. (2000). However, our results show that the strain submitted to the culture collections is pure and our DNA-DNA hybridization experiments clearly identify the L. arizonensis type strain, as deposited in the culture collections, as L. plantarum. The DNA-DNA hybridization experiments confirmed the results of our other investigation methods (rep-PCR, ribotyping and $16 \mathrm{~S}$ rRNA gene sequencing) used to differentiate between the 
species. In addition, all our methods could clearly distinguish between the type or reference strains of $L$. plantarum, L. pentosus and L. paraplantarum. Our investigation clearly shows that the L. arizonensis type strain can not be distinguished from the L. plantarum type strain and other L. plantarum reference strains at the species level. In conclusion, it is proposed that $L$. arizonensis is a later heterotypic synonym of $L$. plantarum and consequently should be renamed.

\section{Acknowledgements}

We thank H. Kline and J. L. Swezey at the ARS Culture Collection for technical assistance. Financial support from the EU Commission within the framework of the INCO RTD programme is gratefully acknowledged. This study was partly carried out under the project 'Improving the quality and nutritional status of GARI through the use of starter cultures and fortification with soybean, palm oil and coconut milk' (ICA4-CT-2002-10058). The work does not necessarily reflect the Commission's views and in no way anticipates the Commission's future policy in this area.

\section{References}

Björkroth, J. \& Korkeala, H. (1996). Evaluation of Lactobacillus sake contamination in vacuum-packaged sliced cooked meat products by ribotyping. J Food Prot 59, 398-401.

Bringel, F., Curk, M. C. \& Hubert, J. C. (1996). Characterization of lactobacilli by Southern-type hybridization with a Lactobacillus plantarum pyrDFE probe. Int J Syst Bacteriol 46, 588-594.

Bruce, J. (1996). Automated system rapidly identifies and characterizes microorganisms in food. Food Technol 50, 77-81.

Curk, M.-C., Hubert, J.-C. \& Bringel, F. (1996). Lactobacillus paraplantarum sp. nov., a new species related to Lactobacillus plantarum. Int J Syst Bacteriol 46, 595-598.

De Ley, J., Cattoir, H. \& Reynaerts, A. (1970). The quantitative measurement of DNA hybridization from renaturation rates. Eur J Biochem 12, 133-142.

Dellaglio, F., Botazzi, V. \& Vescovo, M. (1975). Deoxyribonucleic acid homology among Lactobacillus species of the subgenus Streptobacterium Orla-Jensen. Int J Syst Bacteriol 25, 160-172.

Gevers, D., Huys, G. \& Swings, J. (2001). Applicability of rep-PCR fingerprinting for identification of Lactobacillus species. FEMS Microbiol Lett 205, 31-36.

Hammes, W. P. \& Hertel, C. (2003). The genera Lactobacillus and Carnobacterium. In The Prokaryotes, An Evolving Electronic Resource for the Microbiological Community. Edited by M. Dworkin, S. Falkow, E. Rosenberg, K.-H. Schleifer \& E. Stackebrandt. New York: Springer-Verlag. http://link.springer-ny.com/link/service/books/10125/

Kandler, O. \& Weiss, N. (1986). Regular, nonsporing Gram-positive rods. In Bergey's Manual of Systematic Bacteriology, vol. 2, pp. 1208-1234. Edited by P. H. A. Sneath, N. S. Mair, M. E. Sharpe \& J. G. Holt. Baltimore: Williams \& Wilkins.

Kostinek, M., Specht, I., Edward, V. A., Schillinger, U., Hertel, C., Holzapfel, W. H. \& Franz, C. M. A. P. (2005). Diversity and technological properties of predominant lactic acid bacteria from fermented cassava used for the preparation of Gari, a traditional African food. Syst Appl Microbiol 28, 527-540.

Ludwig, W., Strunk, O., Westram, R. \& 29 other authors (2004). ARB: a software environment for sequence data. Nucleic Acids Res 32, 1363-1371.

Marmur, J. (1961). A procedure for the isolation of deoxyribonucleic acid from microorganisms. J Mol Biol 3, 208-218.

Pitcher, D. G., Saunters, N. A. \& Owen, R. J. (1989). Rapid extraction of bacterial genomic DNA with guanidinium thiocyanate. Lett Appl Microbiol 8, 151-156.

Quere, F., Deschamps, A. \& Urdaci, M. C. (1997). DNA probe and PCR-specific reaction for Lactobacillus plantarum. J Appl Microbiol 82, 783-790.

Rooney, A. P., Swezey, J. L., Wicklow, D. T. \& McAtee, M. J. (2005). Bacterial species diversity in cigarettes linked to an investigation of severe pneumonitis in U.S. military personnel deployed in Operation Iraqi Freedom. Curr Microbiol 51, 46-52.

Sneath, P. H. A. \& Sokal, R. R. (1973). Numerical Taxonomy: the Principles and Practice of Numerical Classification. San Francisco: W. H. Freeman.

Stackebrandt, E. \& Kandler, O. (1979). Taxonomy of the genus Cellulomonas, based on phenotypic characters and deoxyribonucleic acid-deoxyribonucleic acid homology, and proposal of seven neotype strains. Int J Syst Bacteriol 29, 273-282.

Swezey, J. L., Nakamura, L. K., Abbott, T. P. \& Peterson, R. E. (2000). Lactobacillus arizonensis sp. nov., isolated from jojoba meal. Int J Syst Evol Microbiol 50, 1803-1809.

Wayne, L. G., Brenner, D. J., Colwell, R. R. \& 9 other authors (1987). International Committee on Systematic Bacteriology. Report of the ad hoc committee on reconciliation of approaches to bacterial systematics. Int J Syst Bacteriol 37, 463-464.

Yousif, N. M. K., Dawyndt, P., Abriouel, H. \& 7 other authors (2005). Molecular characterisation, technological properties and safety aspects of enterococci from 'Hussuwa', an African fermented sorghum product. J Appl Microbiol 98, 216-228.

Zanoni, P., Farrow, J. A. E., Phillips, B. A. \& Collins, M. D. (1987). Lactobacillus pentosus (Fred, Petersen, and Anderson) sp. nov., nom. rev. Int J Syst Bacteriol 37, 339-341. 